\title{
Water vapor inhibits hydrogen sulfide detection in pulsed fluorescence sulfur monitors
}

\author{
Anders B. Bluhme ${ }^{1, \mathrm{a}}$, Jonas L. Ingemar ${ }^{1, \mathrm{~b}}$, Carl Meusinger ${ }^{1}$, and Matthew S. Johnson ${ }^{1}$ \\ ${ }^{1}$ Department of Chemistry, Universitetsparken 5, University of Copenhagen, Copenhagen, Denmark \\ a now at: DTU Nanotech, Department of Micro- and Nanotechnology, Technical University of Denmark, \\ 2800 Kongens Lyngby, Denmark \\ bnow at: Infuser ApS, Ole Maaløe’s Vej 5, 2200 Copenhagen, Denmark \\ Correspondence to: Carl Meusinger (c.meusinger@gmail.com)
}

Received: 19 November 2015 - Published in Atmos. Meas. Tech. Discuss.: 19 January 2016

Revised: 23 May 2016 - Accepted: 23 May 2016 - Published: 24 June 2016

\begin{abstract}
The Thermo Scientific 450 Hydrogen SulfideSulfur Dioxide Analyzer measures both hydrogen sulfide $\left(\mathrm{H}_{2} \mathrm{~S}\right)$ and sulfur dioxide $\left(\mathrm{SO}_{2}\right)$. Sulfur dioxide is measured by pulsed fluorescence, while $\mathrm{H}_{2} \mathrm{~S}$ is converted to $\mathrm{SO}_{2}$ with a molybdenum catalyst prior to detection. The 450 is widely used to measure ambient concentrations, e.g., for emissions monitoring and pollution control. An air stream with a constant $\mathrm{H}_{2} \mathrm{~S}$ concentration was generated and the output of the analyzer recorded as a function of relative humidity (RH). The analyzer underreported $\mathrm{H}_{2} \mathrm{~S}$ as soon as the relative humidity was increased. The fraction of undetected $\mathrm{H}_{2} \mathrm{~S}$ increased from 8.3 at $5.3 \% \mathrm{RH}(294 \mathrm{~K})$ to over $34 \%$ at $\mathrm{RH}>80 \%$. Hydrogen sulfide mole fractions of 573, 1142, and $5145 \mathrm{ppb}$ were tested. The findings indicate that previous results obtained with instruments using similar catalysts should be re-evaluated to correct for interference from water vapor. It is suspected that water decreases the efficiency of the converter unit and thereby reduces the measured $\mathrm{H}_{2} \mathrm{~S}$ concentration.
\end{abstract}

\section{Introduction}

Hydrogen sulfide $\left(\mathrm{H}_{2} \mathrm{~S}\right)$ is a malodorous, very poisonous, and flammable gas first described by Swedish chemist Carl Wilhelm Scheele (Scheele, 1777). It is produced by the anaerobic bacterial decomposition of organic material, for example in sediments, livestock manure, sewers, and biogas production. In addition, large amounts are given off by hydrodesul- furization in petroleum refineries. It is therefore of great interest to monitor $\mathrm{H}_{2} \mathrm{~S}$ in the atmospheric environment.

Analytical instruments used to quantify $\mathrm{H}_{2} \mathrm{~S}$ include pulsed fluorescence gas analyzers (Harman, 1981), e.g., the Thermo Scientific 450 Hydrogen Sulfide-Sulfur Dioxide Analyzer, in the remainder of this work referred to as the 450. This model has been used in many measurement campaigns worldwide, due to its broad detection range, sensitivity, durability, and reasonable cost. Examples include monitoring $\mathrm{H}_{2} \mathrm{~S}$ emissions from poultry egg laying houses in California (Lin et al., 2012; Ni et al., 2012) as part of the National Air Emissions Monitoring Study (Heber et al., 2009), where odor was also correlated to the measured $\mathrm{H}_{2} \mathrm{~S}$ concentrations (Akdeniz et al., 2012). These studies all utilized Standard Operating Procedure G5 for $\mathrm{H}_{2} \mathrm{~S}$ (Diehl et al., 2006) approved by the Environmental Protection Agency (EPA) for monitoring $\mathrm{H}_{2} \mathrm{~S}$; this protocol advises the use of the 450 . The instrument has also been used to study $\mathrm{H}_{2} \mathrm{~S}$ emissions from anaerobic swine waste treatment (Blunden and Aneja, 2008), and to monitor emissions when altering diets of livestock, including cows and pigs (Li et al., 2011; Liu et al., 2012). Furthermore the 450 has been used to determine $\mathrm{H}_{2} \mathrm{~S}$ removal efficiencies for several air cleaning techniques, including biofilters at pig finishing facilities and swine waste water pits (Akdeniz et al., 2011; Janni et al., 2014; Lim et al., 2012), as well as biotrickling filters in laboratory studies (Liu et al., 2013). Another study monitored $\mathrm{H}_{2} \mathrm{~S}$ concentrations in Reykjavik resulting from two nearby geothermal power plants (Thorsteinsson et al., 2013). 


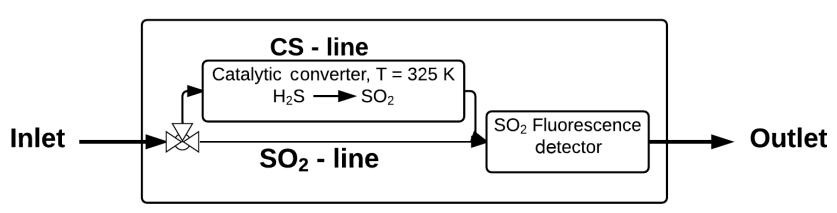

Figure 1. Schematic of the 450 Hydrogen Sulfide-Sulfur Dioxide Analyzer.

The 450 has two internal flow lines: a Combined Sulfur line, referred to as the $\mathrm{CS}$ line, and an $\mathrm{SO}_{2}$ line (Thermo Fisher Scientific, 2008). The CS line directs the sample gas through a converter unit, consisting of a molybdenum catalyst at variable temperatures between 310 and $340^{\circ} \mathrm{C}$, which oxidizes $\mathrm{H}_{2} \mathrm{~S}$ to sulfur dioxide $\left(\mathrm{SO}_{2}\right)$. The $\mathrm{SO}_{2}$ line bypasses the converter, measuring the sample gas directly, as seen in Fig. 1.

The flow system is used in three different measurement modes: $\mathrm{SO}_{2}, \mathrm{CS}$, and $\mathrm{CS} / \mathrm{SO}_{2}$. The $\mathrm{SO}_{2}$ mode only uses the $\mathrm{SO}_{2}$ line, bypassing the converter and therefore only detecting $\mathrm{SO}_{2}$. The CS mode uses only the CS line, passing the gas stream through the converter unit before analysis, thereby detecting the amount of total sulfur in the air stream. When measuring in $\mathrm{CS} / \mathrm{SO}_{2}$ mode, the instrument uses a valve to alternate between the two lines, allowing determination of both $\mathrm{SO}_{2}$ and $\mathrm{CS}$. The $\mathrm{CS} / \mathrm{SO}_{2}$ mode is used to calculate the $\mathrm{H}_{2} \mathrm{~S}$ mixing ratio by subtracting the measured $\mathrm{SO}_{2}$ value from the measured $\mathrm{CS}$ value, assuming that all converted sulfur is $\mathrm{H}_{2} \mathrm{~S}$. However, the converter unit does not oxidize all $\mathrm{H}_{2} \mathrm{~S}$ to $\mathrm{SO}_{2}$, rather it uses a conversion efficiency, $\delta$, determined by the manufacturer. The conversion efficiency varies from instrument to instrument, and is typically above $80 \%$. The conversion efficiency is taken into account when calculating the actual $\mathrm{H}_{2} \mathrm{~S}$ mixing ratio using Eqs. (1) and (2) when measuring in the $\mathrm{CS} / \mathrm{SO}_{2}$ mode.

$$
\begin{aligned}
& \chi_{\mathrm{H}_{2} \mathrm{~S}}=\frac{\chi_{\mathrm{CS}_{\text {detected }}}-\chi_{\mathrm{SO}_{2}}}{\delta} \\
& \chi_{\mathrm{CS}}=\frac{\chi_{\mathrm{CS}_{\text {detected }}}-\chi_{\mathrm{SO}_{2}}}{\delta}+\chi_{\mathrm{SO}_{2}}
\end{aligned}
$$

Here $\chi_{\mathrm{SO}_{2}}$ is the measured $\mathrm{SO}_{2}$ mixing ratio and $\chi_{\mathrm{CS}_{\text {detected }}}$ is the non-compensated CS mixing ratio measured by the 450 .

In CS mode it is assumed that only $\mathrm{H}_{2} \mathrm{~S}$ is present. The 450 therefore uses Eq. (3) to calculate the actual CS concentration of the sample air.

$\chi_{\mathrm{CS}}=\frac{\chi_{\mathrm{CS}_{\text {detected }}}}{\delta}$

The 450 can also be used to measure other reduced sulfur compounds such as methanethiol (MT), dimethylsulfide (DMS), and dimethyl disulfide (DMDS). Gases such as these have different conversion efficiencies than $\mathrm{H}_{2} \mathrm{~S}$.

In this study it is shown that the $\mathrm{H}_{2} \mathrm{~S}$ response of the 450 has a significant interference from water vapor, even at ambient humidities.

\section{Method}

In order to generate test gasses with predetermined $\mathrm{H}_{2} \mathrm{~S}$ mixing ratios and varying relative humidity, flows combining $\mathrm{H}_{2} \mathrm{~S}$ and dried, clean, particle-free ambient air (technical air) were generated using three calibrated mass flow controllers (MFC), as shown in Fig. 2. The $\mathrm{H}_{2} \mathrm{~S}$ concentration was controlled using MFCs 2 and 3, where MFC 3 determined the flow from a $101 \mathrm{ppm} \mathrm{H}_{2} \mathrm{~S}$ flask, while MFC 2 determined the flow of technical air for dilution. A mixing chamber was installed after the two MFCs, which ensured a homogeneous mixture before continuing. Part of the diluted $\mathrm{H}_{2} \mathrm{~S}$ stream was pulled through a Perma Pure Nafion dryer by the 450, while the rest was led to an exhaust, avoiding overpressure on the sample line. The Nafion dryer was used to humidify the dry test gas from the mixing chamber, by allowing water from a humid purge gas to permeate the Nafion membrane in the dryer. The humid purge gas was produced with technical air using MFC 3, where valves A, B, and C controlled the amount of air bypassing or entering a humidifier, before reaching the purge inlet of the Nafion dryer. This made it possible to alter the humidity of the purge gas, and thereby also the amount of water transferred across the Nafion membrane into the test gas.

Preliminary tests showed that the measured $\mathrm{H}_{2} \mathrm{~S}$ concentration was unaffected by the installation of the Nafion dryer. Thus this system was able to produce a constant $\mathrm{H}_{2} \mathrm{~S}$ concentration throughout the experiments, while at the same time, vary the relative humidity.

Once the test gas left the Nafion dryer, the relative humidity $(\mathrm{RH})$ was measured, using a Rotronic $\mathrm{HC} 2-\mathrm{C} 04$ probe with an accuracy of $(\mathrm{RH} \pm 1.5) \%$. After the humidity probe the air stream entered the 450 , which measured the $\mathrm{H}_{2} \mathrm{~S}$ concentration. The instrument used in this study was a model 450i purchased in late 2014, with a stated conversion efficiency of $93.1 \%$. All other materials and instruments used in the experiments are listed in Table 1 (data available at http://data.kb.dk/dvn/dv/AMT-data).

The humidity response of the 450 was tested at three different $\mathrm{H}_{2} \mathrm{~S}$ mole fractions, obtained by adjusting the flows from MFCs 2 and 3. All measurements were conducted in CS mode, since only $\mathrm{H}_{2} \mathrm{~S}$ was present in the sample gas. The three initial $\mathrm{H}_{2} \mathrm{~S}$ mole fractions were $573 \pm 4$, $1142 \pm 3$, and $5145 \pm 8 \mathrm{ppb}$. These measured values are close to the nominal mixing ratios of: $513 \pm 26,1019 \pm 51$, and $4756 \pm 238 \mathrm{ppb}$, calculated from MFC settings and the stated gas flask concentration. The uncertainties of the MFCs were not included in these calculations, which could explain the observed offset.

In each experiment the $\mathrm{H}_{2} \mathrm{~S}$ mixing ratio was measured initially under completely dry conditions, meaning that the two valves leading to and from the humidifier (valves B and C) were closed, while the bypass valve (A) was open. Once a stable concentration was obtained, measurements continued for $20-30 \mathrm{~min}$, ensuring sufficient data for 


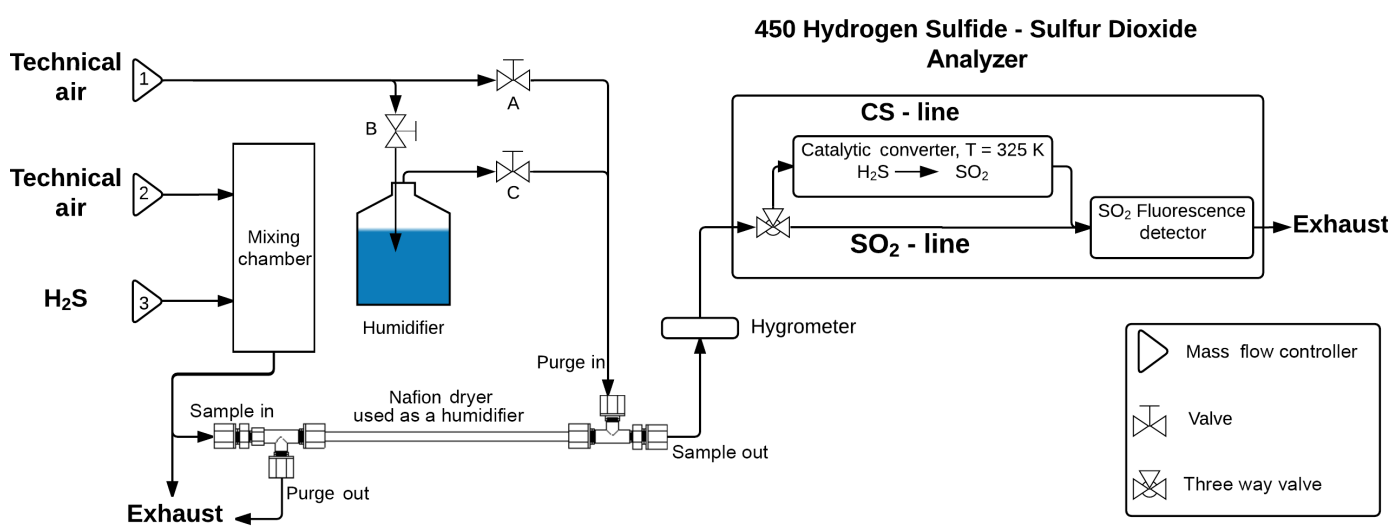

Figure 2. Schematic of the experimental setup.

Table 1. List of materials and instruments used in the experimental setup.

\begin{tabular}{lll}
\hline Item & Manufacturer & Description \\
\hline $\mathrm{H}_{2} \mathrm{~S}$ gas & Yara Praxair & $\mathrm{H}_{2} \mathrm{~S}$ in nitrogen, certified 101 ppm $\pm 5 \%$ \\
$\mathrm{SO}_{2}$ gas & Yara Praxair & $\mathrm{SO}_{2}$ in synthetic air, certified 42 ppm $\pm 5 \%$ \\
$\mathrm{MFC}-1$ & Brooks Instrument & Model: 4800 0-3 L min \\
$\mathrm{MFC}-2$ & Brooks Instrument & Model: 5850TR 0-10 L min \\
MFC-1 & Brooks Instrument & Model: 5850S 0-100 mL min \\
Nafion dryer & Perma Pure & Model: MD-110-24F-4, 24" dryer \\
\hline
\end{tabular}

analysis. The humidity was then increased by slightly opening valves $\mathrm{B}$ and $\mathrm{C}$. The system was allowed to equilibrate, typically for 30-60 min, followed by another 20-30 min of measurements at stable $\mathrm{H}_{2} \mathrm{~S}$ concentration and humidity. The procedure was repeated for several different humidities, with a stable temperature in all experiments of $294.2 \pm 0.8 \mathrm{~K}$.

\section{Results and discussion}

In all experiments the $\mathrm{H}_{2} \mathrm{~S}$ mixing ratio decreased within 12 min of increasing the humidity of the test gas, showing that the 450 responds very quickly to changes in water content of the sample air.

The ratio between the $\mathrm{H}_{2} \mathrm{~S}$ mole fractions measured at wet and dry conditions were plotted against the relative humidity in Fig. 3. Even at a very low relative humidity, 5.3\%, $\mathrm{H}_{2} \mathrm{~S}$ decreased from 5145 to $4718 \mathrm{ppb}$, corresponding to a reduction of $8.3 \%$ in measured $\mathrm{H}_{2} \mathrm{~S}$. Higher reductions were observed when increasing the humidity further, showing an almost linear correlation between the increase in humidity and the decrease in $\mathrm{H}_{2} \mathrm{~S}$ mole fraction. At all three initial mixing ratios more than $34 \%$ of the $\mathrm{H}_{2} \mathrm{~S}$ concentration passed the instrument undetected when measuring at relative humidities above $80 \%$. The largest decrease was observed at the high initial $\mathrm{H}_{2} \mathrm{~S}$ mole fraction, indicating that the effect could be even greater at higher concentrations.

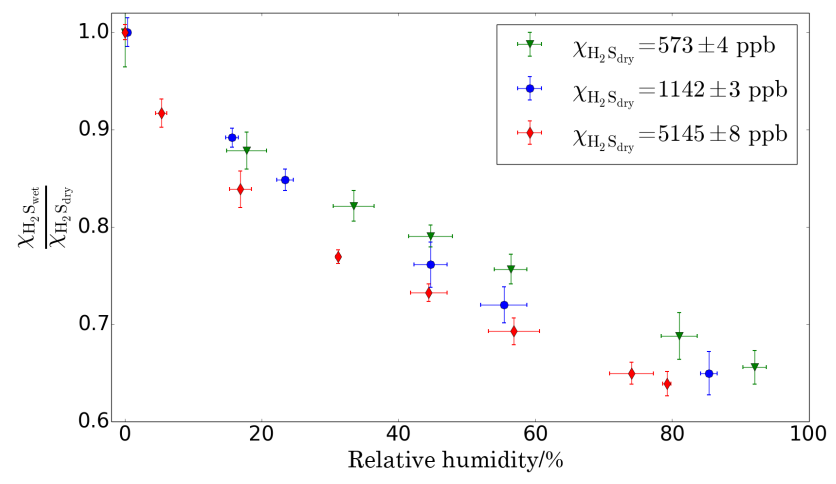

Figure 3. The ratio between measurements of $\mathrm{H}_{2} \mathrm{~S}$ at wet and dry conditions for three initial mole fractions, plotted against the corresponding humidity at a temperature of $294.2 \pm 0.8 \mathrm{~K}$. All error bars have been multiplied by 5 for better visualization.

A similar experiment was conducted with $\mathrm{SO}_{2}$ instead of $\mathrm{H}_{2} \mathrm{~S}$, and no interference from water was observed. This led to the conclusion that the interference from water was produced in the converter unit, possibly due to inhibition of catalytic sites, thereby lowering the conversion efficiency. According to our observations it is not necessary to dry the sample air when measuring $\mathrm{SO}_{2}$.

The interference from water calls earlier studies into question, unless the sampling was performed under completely 
dry conditions. However, since a significant reduction was observed in $\mathrm{H}_{2} \mathrm{~S}$ at only $5.3 \%$ relative humidity, virtually all ambient measurements may be complicated by the interference of water vapor. The interference from water is not mentioned in the instrument manual; instead it is stated that the instrument functions at ambient conditions. Therefore most researchers do not dry sample air before measuring, meaning that many earlier studies may have underreported $\mathrm{H}_{2} \mathrm{~S}$ levels. The fast response to changes in humidity could make events such as rainfall result in significant underreporting of $\mathrm{H}_{2} \mathrm{~S}$ concentrations. Furthermore the interference could result in overestimations of removal efficiencies for certain biofilters, where high humidities are necessary for the filters to function. Our measurements indicate that the Standard Operating Procedure provided by the US Environmental Protection Agency, should be revised to account for the water vapor interference. The water vapor interference may also occur in instruments that utilize a similar technique such as the Teledyne $\mathrm{T} 101 \mathrm{H}_{2} \mathrm{~S}$ Analyzer (Teledyne, 2012), but this was not tested in the present study. It should be noted that the magnitude of the effect is likely to vary from one instrument to another, seeing that the effect is determined by the state of the catalyst. Furthermore it is not clear how many instruments are affected, and users should therefore investigate if similar behaviors are observed in their instruments.

\section{Conclusions}

It has been shown that a Thermo Scientific 450 Sulfur Analyzer shows a significant water vapor interference when measuring $\mathrm{H}_{2} \mathrm{~S}$. Reductions of up to $1 / 3$ of the dry $\mathrm{H}_{2} \mathrm{~S}$ mixing ratio were observed at ambient conditions. Our opinion is that the interference occurs in the catalytic unit converting $\mathrm{H}_{2} \mathrm{~S}$ to $\mathrm{SO}_{2}$. These findings indicate that earlier results obtained with the 450 and similar instruments are very likely to have underreported $\mathrm{H}_{2} \mathrm{~S}$ concentrations and should therefore be re-evaluated. Since the magnitude of the effect is most likely instrument-specific and since it is not clear how many instruments are affected, users of the 450 should investigate the behavior of their own instruments. Based on these findings it is recommended to dry the air stream prior to a catalytic $\mathrm{H}_{2} \mathrm{~S}$ monitoring instrument using a Nafion dryer, which in this study was shown to produce no change in the measured $\mathrm{H}_{2} \mathrm{~S}$ concentration. Alternative drying techniques were not tested in this study and should therefore be experimentally verified before use.

\section{Data availability}

All experimental data is available online (Bluhme et al., 2016; http://data.kb.dk/dvn/dv/AMT-data).
Acknowledgements. The authors would like to thank the Copenhagen Center for Atmospheric Research (CCAR) at University of Copenhagen for their help and support. Furthermore they would like to thank the Innovation Fund Denmark (grant number 156-2013-6) for their financial support.

Edited by: P. Herckes

\section{References}

Akdeniz, N., Janni, K. A., and Salnikov, I. A.: Biofilter Performance of Pine Nuggets and Lava Rock as Media, Bioresource Technol., 102, 4974-4980, 2011.

Akdeniz, N., Jacobson, L. D., Hetchler, B. P., Bereznicki, S. D., A. J. Heber, Koziel, J. A., Cai, L., Zhang, S., and Parker, D. B.: Odor and Odorous Chemical Emissions from Animal Buildings: Part 6. Odor Activity Value, Transactions of the American Society of Agricultural and Biological Engineers, 55, 2357-2368, 2012.

Blume, A. B., Ingemar, J. I., Meusinger, C., and Johnson, M. S.: Supplementary Information: Water vapor inhibits hydrogen sulfide detection in pulsed fluorescence sulfur monitors, http://hdl. handle.net/109.1.1/10151, 2016

Blunden, J. and Aneja, V. P.: Characterizing Ammonia and Hydrogen Sulfide Emissions from a Swine Waste Treatment Lagoon in North Carolina, Atmos. Environ., 42, 3277-3290, 2008.

Diehl, C. A., Bogan, B. W., Grant, R. H., and Boehm, M. T.: EPA Standard Operating Procedure G5: Measurement of Hydrogen Sulfide $\left(\mathrm{H}_{2} \mathrm{~S}\right)$ with the Thermo Electron Corporation Model 450I Pulsed-Fluorescence Analyzer, Tech. rep., Agricultural and Biological Engineering, Purdue University, West Lafayette, IN, USA, 2006.

Harman, J. N.: Interference Reactor to Provide Selective $\mathrm{SO}_{2}$ Measurement by Fluorescent Methodology, U.S. Patent No. 4, 272, 486.9, 1981.

Heber, A., Bogan, B., Ni, J.-Q., Lim, T.-T., Cortus, E., RamirezDorronsoro, J., Diehl, C., Hanni, S., Xiao, C., Casey, K., Gooch, C., Jacobson, L., Koziel, J., Mitloehner, F., Ndegwa, P., Robarge, W., Wang, L., and Zhang, R.: The National Air Emissions Monitoring Study: overview of barn sources, in: Livestock Environment VIII, Am. Soc. Ag. Bio. Eng., 1990-206, doi:10.13031/2013.25499, 2009.

Janni, K. A., Jacobson, L. D., Hetchler, B. P., Oliver, J. P., and Johnston, L. J.: Semi-Continuous Air Sampling versus 24-Hour Bag Samples to Evaluate Biofilters on a Swine Nursery in Warm Weather, Transactions of the American Society of Agricultural and Biological Engineers, 57, 1501-1515, 2014.

Li, W., Powers, W., and Hill, G. M.: Feeding Distillers Dried Grains with Solubles and Organic Trace Mineral Sources to Swine and the Resulting Effect on Gaseous Emissions, J. Anim. Sci., 89, 3286-3299, 2011.

Lim, T. T., Jin, Y., Ni, J. Q., and Heber, A. J.: Field Evaluation of Biofilters in Reducing Aerial Pollutant Emissions from a Commercial Pig Finishing Building, Biosyst. Eng., 112, 192-201, 2012.

Lin, X. J., Cortus, E. L., Zhang, R., Jiang, S., and Heber, A. J.: Ammonia, Hydrogen Sulfide, Carbon Dioxide and Particulate Matter Emissions from California High-Rise Layer Houses, Atmos. Environ., 46, 81-91, 2012. 
Liu, C., Liu, J., Li, J., He, H., Peng, S., Li, C., and Chen, Y.: Removal of $\mathrm{H}_{2} \mathrm{~S}$ by Co-Immobilized Bacteria and Fungi Biocatalysts in a Bio-Trickling Filter, Process Saf. Environ., 91, 145$152,2013$.

Liu, Z., Powers, W., Oldick, B., Davidson, J., and Meyer, D.: Gas Emissions from Dairy Cows Fed Typical Diets of Midwest, South, and West Regions of the United States, J. Environ.1 Qual., 41, 1228-37, 2012.

Ni, J. Q., Chai, L., Chen, L., Bogan, B. W., Wang, K., Cortus, E. L., Heber, A. J., Lim, T. T., and Diehl, C. a.: Characteristics of Ammonia, Hydrogen Sulfide, Carbon Dioxide, and Particulate Matter Concentrations in High-Rise and Manure-Belt Layer Hen Houses, Atmos. Environ., 57, 165-174, 2012.
Scheele, C. W.: Die Stinckende Schwefel Luft, Chemische Abhandlung von der Luft und dem Feuer, 97, 149-155, 1777.

Teledyne: Operation Manual Model T101 UV Fluorescence $\mathrm{H}_{2} \mathrm{~S}$ Analyzer, 2012.

Thermo Fisher Scientific: Model 450i - Instruction Manual, 2008.

Thorsteinsson, T., Hackenbruch, J., Sveinbjörnsson, E., and Jóhannsson, T.: Statistical Assessment and Modeling of the Effects of Weather Conditions on $\mathrm{H}_{2} \mathrm{~S}$ Plume Dispersal from Icelandic Geothermal Power Plants, Geothermics, 45, 31-40, 2013. 